Jose Francisco Lazo M.

\title{
El impacto de la nueva revolución tecnológica en el tercer mundo
}

La organización del trabajo se ha eatructurado de la siguiente manern: on in primera parte se presenta la concepción sobre lo que implica une revolución tecnológica (RT). La segunda parte contiene la apreciación de diversos autares sobre la Nueva Revolución Tecnológica (NRT). Al final se hace una valoración general sobre la temática de las nuevas tecnologias y sus implicaciones en las economías atrasadas.

\section{Que Implice ane revoluctón tecnolodica}

El desarrollo de las fuerzas productivas sigue una tendencia de avance, que se manifiesta en una generación constante e inintermumpida de nuevos métodos de producción que posibilitan, con cada nuevo paso que se de, una mejora en los procesos productivos que tienden a hacer, entre otras cosas, miss productivo el trabajo, ahorrar mano de obre, abaritar los productos, genera nuevos bienes y servicios, modificar la división internecional del trabajo, etc.

Desde la dtcada de los setenta se viene configunndo una nueva revolución tecnologica (NRT). Las revoluciones tecnologicas (RT) se entienden de la manen aiguiente: "Parn que un conjunto de nuevas tecnologias genere una revolución tecnológica y, por ende, constituya un núcleo de tecnologías básicas, debe cumplir los siguientes requisitos: (a) conducir a muchos nuevos productos; (b) transformar la mayorla de los procesos productivos; (c) ser aplicables en muchos sectores de la economí; (d) disminuir los obstáculos para el crecimiento del núcleo anterior" (Mertens, 1991).

Otra visión complementaria es la siguiente: son elementos "que transforman profundamente el sistems socioeconómico en casi todos sus aspectos [más alla de lo puramente económico], gracias a las innovaciones que se implementaron a partir de los procesos competitivos [entre frecciones de capital y entre capital y trabajol para reducir los costos e incrementar la ganancia media... que además vinieron acompaniadas o precedidas por profundas mutaciones en las relaciones 
sociales... [las revoluciones tecnológicas] no se dieron ni se dan todos los días, sino que aparecen de manera muy espaciada en el tiempo, en forma de manadas de innovaciones" (Schuld, 1992).

"La introducción de cambios tecnológicos en productos, procesos, materias primas y equipos constituye un fenómeno constante y cotidiano, en tanto afecta las condiciones especificas de una unidad productiva o de un sector. En la misma medida en que dichos cambios tienen un ámbito restringido de aplicación, sus efectos se limitan, casi exclusivamente, a la esfera de los factores económicon laborales y sociales directamente vinculados. En cambio, en algunas circunstancias, la modificación sustantiva de los contenidos cientficos y tecnológicos en los que se basa la organización de la producción, constituye una verdadera revolución y forma parte, promueve y condiciona profundas repercusiones en las dimensiones económicas, sociales, culturales y politicas de la totalidad de los sectores y paises, y de las relaciones entre ellos" (Tangelson, 1992).

En todo caso, no se trata de agotar la totalidad de los elementos que diversos téricos toman en cuenta en el momento de definir lo que es una revolución tecnológica, sino de dejar sentado que existen diversas interpretaciones, la mayor parte de ellas complementarias entre sl, sobre lo que comprende la revolución tecnológica.

De acuerdo con la teoría de D. Ricardo, el mercado libre, internacional favorecería la división internacional del trabajo, según la cual cada pals se especializara en aquellos bienes que, por sus condiciones nàturales, podrfa producir con ventaja comparativa sobre los demás. Pare Ricardo habrfa que tomar en cuenta las condiciones naturales de cada pars o región. Pero graclas al desarrollo cientsfico, las dotaciones naturales han experimentado tremendas transformaciones y con el trenscurso del tiempo resulte diffcil mantener en su forma pura la concepción ricardiana del comereio. En muchos parses, las ventajas naturales han sido sustituidas por ventajas adquiridas, es decir, que son producto del avance lecnológico; mientras que otras regiones siguen contando únicamente con sus tradjcionales ventajas naturales, situación que les permite continuar inserlos en el mercado internacional. Esta situación se ha presentado hasta la presente dócada, y ha permitido que aquellos países que han evolucionado hacia la puesta en vigencia de ventajas adquiridas, el progreso tecnológico se haya desarrollado, mientras que en aquellas regiones donde continúan predominando las ventajas naturales, existe un notable retraso tecnológico. Esta situación explica, en parte, el deterioro de los términos de intercambio de los bienes primarios en comparación con los industriales o producidos mediante avances tecnológicos.

Con cada revolución tecnológica, el deterioro de los términos de intercambio de los bienes primarios se acentúa, y la brecha tecnologica entre el primer mundo y el resto de países se ensancha. En buena medida, la división del mundo -manifestada por una minorfa que se considera desarrollada y rica, y otra, la 
mayor parte, que es subdesarrollada y tremendamante pobre- tiene su explicación, entre otras cosas, por la brecha tecnologica que las separa. En este aspecto se hace referencia a la nueva polaridad mundial que se evidencia en las postrimerfas del siglo XXX, que es la definida por el norte-sur, en contraposición a la polaridad que existio entre el final de la Segunda Guerra Mundial y 1990, que fue la Guerra Fría entre el este y oeste.

El desarrollo tecnológico no puede considerarse como inocuo en términos sociales, sino que genera importantes efectos socioeconómicos y polfticos; la división norte-sur asi lo manifiesta. De alli que pueda decirse que la ciencia no es neutral. Muchos adelantos, sino es que la mayorfa de los que se generan, se traducen en acentuar las tremendas diferencias entre rioos y pobres, entre el desarrollo y el subdesarrollo, entre el norte y el sur, etc. El hecho de tener acceso o generar adelantos tecnológicos permite a una sociedad enfrentar de mejor manera los retos del futuro, máxime los derivados del proceso de globalización.

Diversos teóricos, que han estudiedo los impactos de las diversas revoluciones tecnológicas, no coinciden en cuanto al número de éstas - unos se refieren a tres y otros a cinco-, pero si coinciden en que la última se inició a mediados de los setenta, y consistió en los avances en la microelectrónica, la biotecnología y los nuevos materiales.

Dentro de las posiciones que indican que han habido únicamente tres revoluciones tecnologicas (RT) se menciona la siguiente: pueden identificarse varias RT; la primera se identifica con la Revolución Industrial, la segunda con la aparición del motor de combustión interna y de la electricidad, y la última con la microelectrónica, la biotecnologia y los nuevos materiales. La aplicación de cada una generó una profunda transformación en la vida de la sociedad y en la forma en que se organiza la producción; igualmente toda revolución tecnológica genera importantes cambios en la división internacional del trabajo.

Otros llegan a identificar hasta cinco revoluciones tecnológicas y las asocian con las ondas largas de Kondratiev. Al respecto se pueden hacer las valoraciones siguientes (Schuldt, 1992; ver Gráfica 1):

"l. La primera y segunda rovoluciones tecnológicas fueron lidereadas por Inglaterra; la tercera por Estados Unidos y Alemania; la cuarta por Estados Unidos, Alemania y Japón (con el acompañamiento de la Comunidad Europea). Ello indica una mayor homogeneización entre los países capitalistas desarrollados. La primera revolución tecnologica duró unos 41 años, de 1787 a 1828; se basó en el carbón, el motor de vapor y los textiles. La segunda, unos 58 años, de 1828 a 1885; se transformó el área del transpone, de ferrocarriles y vapores, se pasó de la producción concurrencial a la competencia monopolistica y al imperialismo. La tercera duró 53 años, de 1886 a 1938; se sustentó en el motor de 


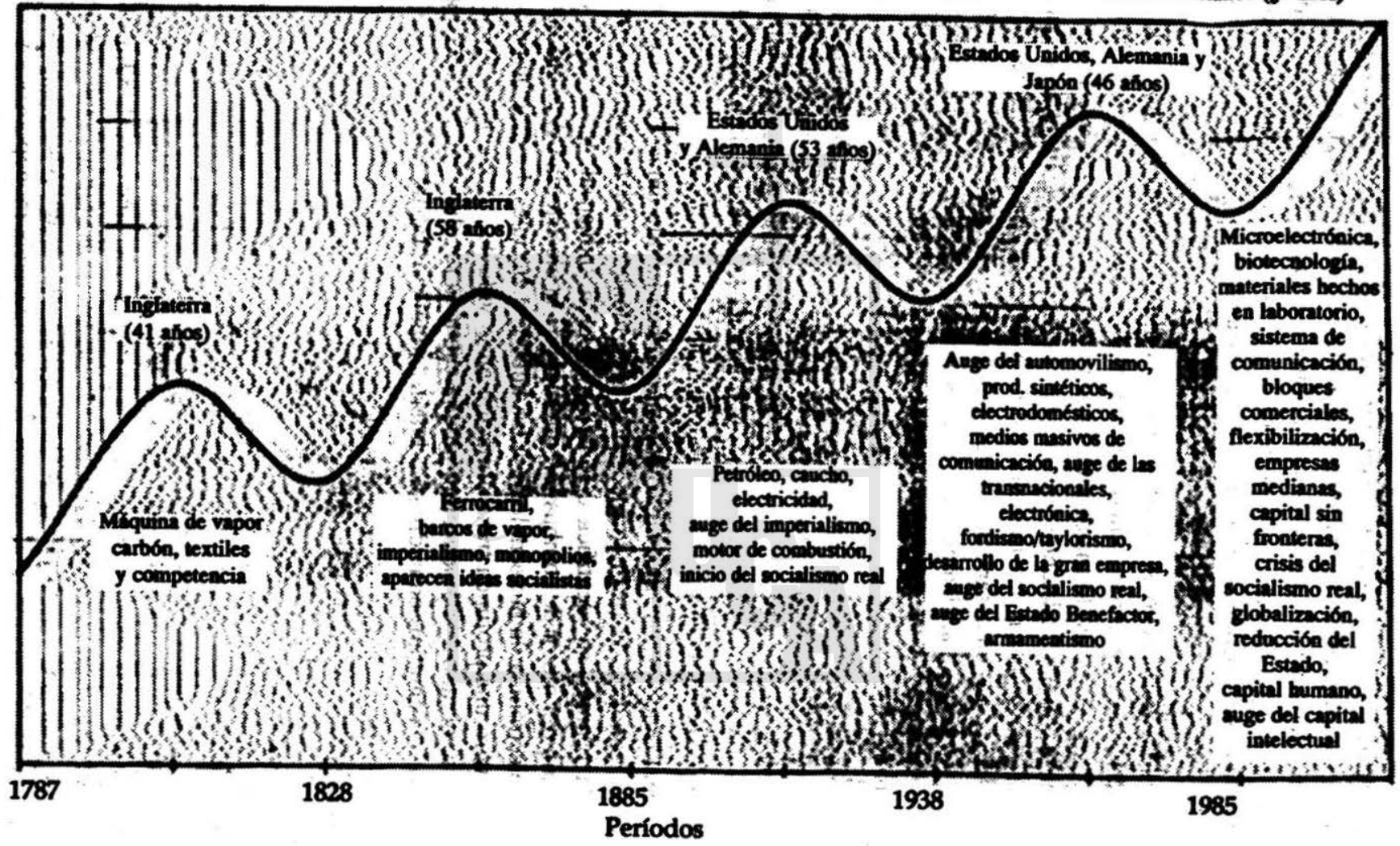

Digitalizado por Biblioteca "P. Florentino Idoate, S.J."

Universidad Centroamericana José Simeón Cañas 
combustión, la explotación del caucho, petróleo y del uso intensivo de la electricidad; fue el auge del imperialismo y marea el paso de la libre esterlina al dolar. La cuarta revolución tecnologica, de 46 afios al menos, ide 1939 a 1985?, se desarrollo a partir del motor de explosión con el auge del automóvil, los insumos y productos sintéticos, la electrónica y los medios masivos de comunicación. La economla se internacionaliza y existe el predominio de las empresas transnacionales. La quinta es la que estamos viviendo a partir de 1980.

2. Las fases de la crisis en el interior de cada onda larga no muestran -en promedio- tasas negativas de crecimiento económico, sino que son mucho menores que en la fase de auge.

3. El énfasis en las revoluciones tecnológicas como fundamento motor y reclor de cada onda larga no debe soslayar el hecho de que ellas no se dan en el vacio y que, finalmente, sus especificidades son resultado del conflicto intercapitalista y del que se genera entre el capital y el trabajo, a nivel nacional e internacional.

4. Cada revolución tecnológica representa una innovación destructiva, de acuerdo con la visión shumpeteriana, en el sentido de que su materialización convierte en obsoletas las inversiones productivas previas, mismas que sustentaron a la RT anterior. Como tal, implican conflictos entre fracciones del capital a nivel nacional $e$ internacional.

5. Implican transformaciones importantes en la division del trabajo (en las empresas, la nación o del mercado internacional), de la relación Estado-Sociedad Civil, para el desarrollo cientifico sobre los impactos en los valores, normas y expectativas de la población, elc. Esto repercule en los paises perifericos, como los de América Latina, en el sentido que determinan el tipo de especialización que le conviene, el rol que desempeña la inversión extranjera directa, el lipo de exportaciones, el rol de la sustitución de importaciones, el rol del Estado, etc.

6. Por lo general, las bases de una nueva revolución tecnológica se asientan en la fase de crisis de la anterior.

7. La historia nos enseña que en la fase de auge de la onda larga domina el capital invertido productivamente, mientras que en la fase de descenso adquiere preponderancia el capital financiero".

De lo anterior se puede deducir que las revoluciones tecnológicas son inherentes al desarrollo de las formas productivas a todo nivel, es decir, que no se encuentran determinadas por la forma de organización social de que se trate -capitalismo o socialismo- ya que en todos los sistemas se sienten sus repercusiones. Cabe destacar que las motivaciones obedecen más a necesidades del capitalismo en el sentido de que tratan de recuperar la calda de la tasa de ganancia. Pero tambien 
el entorno tiene elementos deterministas, dado que las revoluciones tecnologicas ponen a desarrollar el ingenio humano para superar determinados cueltos de botella o mejorar las condiciones de producción que es una virtud del raciocinio humeno.

La revolución tecnológica más reciente, basada en los tres elementos ye mencionados si bien es cierto que todavía no se encuentra en todo su esplendor, sf se puede afimar que se esta gestando sobre la fase de crisis de una onda larga, que se puede definir por los elementos de la decadencia del esquema que logro el auge de la posguerra, sus bases se desmoronan, Bretton Woods, la perdida de hegemonla del dólar, el auge del capital financiero (crisis de lo deuda). A finales de la década de los ochenta, del total de movimientos de capilal que se genernron a nivel internacional, apenas 4 por ciento correspondieron al comercio de bienes y servicios, el restante 96 por ciento obedeció a movimientos de capital financiero entre las diversas bolsas, por lo tanto, en la fase actual del capitalismo es mís importante el capital financiero-especulativo que el productivo.

\section{L Nueva Revolución Tecoologica (NRT)}

Diversos autores' coinciden en que los avances cientificos en los campos de la microelectrónica, la biotecnologia y los nuevos materiales y en su continuado apoyo y divulgación a los procesos productivos, permiten que se hable de que se esth en presencia de una Nueva Revolución Tecnologica (ver Grafica 1) que, por tanto, implica la entrada a una nueva fase de recuperación económica, es decir, a una etapa de recuperación del crecimiento económico de una troeva onda larga, que necesariamente afectará la actual division intermecional del trabajo, la organización de la producción, les releciones socinlen, la funciba del Extado, las relaciones norte-aur, la dirección y el contenido de les trunsacciones internacionales, las comunicaciones, las releciones de poder ea el compo internaciomal, elc.

"La microelectrónica usada en los procesos productivos, así como en los diferentes sectores de la economía ya no es una novedad, desde el sector agrícola pasando por la industria hasta el sector servicios, encontramos cambios importantes en el proceso de produccion al introducirse equipo basado en mictoelectrónica. Actualmente aproximadamente 80 por ciento de la producción de los palses industrializados ha involucrado algún equipo basado en la electrónica. La biotecnología se está proyectando como la revolución tecnológica del mañana. La nueva dimensión consiste en la manipulación de los oódigos genéticos de los seres vivos, la cual se combina e integra con tecnología de fusión de ctlulas en donde se pueden combinar características de varias celulas en una sola, asi como tumbién con tecnologla enzimática y de fermentación. Los nuevos materiales, donde las fibras ópticas, fíbras de carbón, nuevos plásticos, láser, productos cerémicos, son algunos de los avances en la ciencia de materiales que ya han encontrado su aplicación en los procesos productivos y en produclos" (Mertens, 1991). 
La aplicación de esta NRT se basa, de manera fundamental, en el desarrollo y avance del conocimiento cientifico que conduce a sistemas de producción altamente integrados. Por otra parte, al tener aplicación en los tres sectores tradicionales en que se ha dividido la economfa -primario, secundario y terciario-, donde sus tres componentes - microelectronica, biolecnologia y nuevos materiales- tienen plene utilización on los tres sectores, se tiende a desvanecer la frontern que dividin a dichoe sectores. "Las tradicionales divisiones en sectores de la cocnomia empiesnn a diluirse. La tecnologia usada en la granja, la fábrica y la oficina del futuro, convergirán. En la automatización de la fábrica y la oficina se perfila una integración tecnológica muy fuerte para los proximos âtos, usando una computadora en la gestión de la misma. El uso, en la granja, de la biotecnologla junto con la microelectrónica, la hara parecer más y más a una fabrica. En un futuro no muy lejano (¿en el 2030?), habre un traslapo grande entre la granja, la fábrica y la oficina, usando biochips y biocomputadoras para aplicaciones muy avanzadas y complejas" (Mertens, 1991).

"El nuevo paradigma tecnoeconómico, en el que la microelectronica en sus distintas aplicaciones (robotice, informática, artefactos del hogar, telemátice, telecomunicaciones, etc.), y la información desempeñan el rol central articulador de la acumulación y como elemento condicionante de la peculiar dinárnica económica y politica que condicionarfa los eventos de las próximas décadas. Igualmente las nuevas tecnologias de materiales, la biotecnologla, las novedosas fuentes de energía, etc. se vienen constituyendo en elementos que están transformando de manera importante los procesos prodictivos. Tienen en común el hecho de que se basan fuertemente en el conocimiento cientifico-tecnológico y que conducen a sistemas de producción altamente integrados" (Schuldt, 1992).

La NRT repercute en las relaciones sociales de producción, dado que "se está pasando del fordismo al pasfordismon. Es decir, pasar de lo que el fordismo tenía como caracteristicas que se pueden resumir en las siguientes: la producción masiva basada en el principio de la línea de montaje; salarios en aumento que provefan las bases para uma nueva articulación entre la producción y el consumo masivo; grandes fabricas; un alto grado de intervención estatal fincada en principios keynesianos; el desamollo del Estado do Bienestar, un papel central de los sindicatos en la institucionalización de la contratación colectiva y en la formulación de politicas estatales.

Las características que exige el posfordismo son: empleo de nuevos mélodos de producción basados en la microelectrónica; prácticas de trabajo lexibles; un papel social muy reducido para los sindicatos, incluso ya hay nuevas formas de organización laborales, como son las originadas por el solidarismo; un nuevo individualismo; una intervención estatal reducida; una nueva relación entre produción y consumo" (Bonefeld y Holoway, 1994). 
Este cambio del fordismo al posfordismo implica serias transformaciones en la organización de la producción, entre las que destacan las siguientes:

(a) Las empresas integran en una sola las tres áreas básicas del diseffo de la producción, el proceso productivo y la gestión empresarial. La informática, las herramientas de control numérico y los robots contribuyen a facilitar eata conjunción. Se posibilita la producción de lotes pequefios de manern flexible. Esta situación conduce a que las tradicionales ventajas que trafa consigo ef fordismo, basadas en las oconomlas de escala con tecnicas intensivas en capital, pierdan significado.

(b) En la producción flexible, posfordista, el trabajador debe tener capacidad polivalente o multiespecializada. Ya no se hablará de un puesto de trabajo especffico y único, sino de una situación de trabajo en que un equipo o grupo de trabajadores colaboran y tienen responsabilidad completa por un subproducto completo.

(c) Se modifican las interacciones entre las empresas, en las que la subconsratación y las releciones estrechas con los proveedores desempeffan un rol central.

Como puede desprenderse, esta NRT no es neutral, ni en su origen (alianza de empresas multinacionales y gobiernos nacionales), ni en sus consecuencias pare la clase obrera tanto de los passes centrales, como de los periféricos. Se avecina, por lo tanto, una nueva división internacional del trabajo donde las repercusiones serán de consecuencias nefastas para los paises productores de bienes primarios, que se verán en mayores dificultades para lograr una inserción adecuada en el mercado internacional.

Los efectos que tendrá son variados, entre ellos se pueden destacar los siguientes:

(a) Nueva división internacional del trabajo. "Un anślisis comparativo de la proporcion en que los productos con alto contenido tecnológico participan del total de las exportaciones en los parees integrantes de la OCDE, pone de relieve la modificación de la posición relativa de dichos palses. En 1963, Estados Unidos presentaba un índice de 129; la CEE, 102 y Japon apenas 56 , sobre la base de un promedio de 100 para el conjunto de la OCDE. Hacia 1980, Estados Unidos desciende a 120, la CEE a 88, mientras que Japón experimenta una considerable alza al tener un indice de 141" (Thurow, 1992). Sobre esta base, Thurow pone de manifiesto que la guerra que se avecina para el próximo milenio se dará en términos económicos sobre la base de la aplicación de los adelantos de la NRT, donde los paises atrasados quedarán a la expectativa, a lo sumo podrían incorporarse en alguno de los intentos de regionalización de mercados que en estos momentos se están desarrollando. Los paises del centro y este europeo podrían integrarse a la 
CEE; los asiáticos, al eje que comanda Japón; los latinoamericanos al NAFTA o podrían acomodarse a la propuesta que surgí en diciembre de 1994 . con ocasión de la Cumbre de las Américas, donde el compromiso fue la creación de una región de libre comercio hacia el año 2005.

(b) Efectos socioeconómicos. Las revoluciones tecnologicas traen aparejado tremendos cambios en los ámbitos social y económico lo cual implica que unos sectores poblacionales queden rezagados respecto a otros, que unos países se adelanten a otros, que los niveles de ingreso se ensanchen, etc. El nivel de empleo experimentará una reducción por la mayor automatización del proceso productivo. Por ejemplo, en la industria del calzado en México se diseñan y cortan entre 18 y 22 mil pares de zapatillas al día con sólo seis operarios. El correo electrónico en Canadá creará 30 mil empleos en 10 años, peru suprimirá 500 mil enure los carteros tradicionales, en otras palabras, habrá una pérdida neta de $\mathbf{4 7 0}$ mil empleos. Gracias a la biotecnología se puede homogeneizar el proceso de maduración de los vegetales, lo cual conduce a un menor requerimiento de mano de obra durante la cosecha. Además, disminuirá la capacidad exportadora de productos tradicionalmente intensivos en mano de obra, que serán producidos en los palses desarrollados mediante la aplicación de la robotización. Se requerirá una mayor calificación de la mano de obra. En contraposición se espera un incremento de las actividades informales urbanas.

(c) Distribución del ingreso y estructura del consumo. Se espera que con la NRT se acreciente la desigual concentración de ingresos tanto a nivel funcional como personal. Robert Reich, Secretario del Trabajo de la Administración Clinton, indica que dentro de la nueva jerarquización de la división del trabajo, serán los Analistas Simbólicos — aquellos que se dedican a resolver problemas, a pensar en futuros cuellos de botella y adelantarse a su solución, a generar nuevos problemas - (que además resulta ser una actividad que debe ser vista como hija natural de la NRT), serán los jerarcas en la apropiación de ingresos, mientras que los tradicionales puestos continuarán en su ya estructurada diferenciación, por lo tanto, se incrementará la brecha de ingresos existentes en donde los Analistas Simbólicos superan con creces a la brecha que mantenían los actuales directores respecto de los obreros (Reich, 1993).

Aunado a lo anterior, al tomar en cuenta la reducción del empleo por la aplicación de la NRT y la expansión de las actividades informales, con menores niveles de productividad, estos amplios sectores tendrán acceso a una proporción cada vez menor del ingreso nacional.

(d) Sistema educativo. El sistema educativo tradicional, cuya preocupación básica era enseñar a leer y escribir y resolver las operaciones matemáticas elementales, debe modificarse y transformarse por uno que privilegie el apren- 
der-haciendo, es decir, que califique para el trabajo modemo. En este punto cabe una digresión: cuando se inició la era del automovil muy pocos sabían manejar y éstos eran considerados como privilegiados; en estos momentos del desarrollo de la era automovilistica quien no sabe manejar está fuera del mercado de trabajo en muchos aspectos; con el inicio de la informática, aquél que sabía operar una computadora era considerado alguien excepcional, hacia mediados de la década de los noventa, quien no sabe está fuera del mercado de trabajo dinámico. Por tanto, los sistemas educativos deben ponerse a la par de ciertos avances que implica la NRT. Por ejemplo, en Costa Rica, la enseñanza de computación es obligatoria en el área urbana y rural desde la primaria, y ello ha colocado a este pals muy por arriba del resto de países centroamericanos para enfrentar los retos de la reconversión productiva

(e) Las organizaciones sindicales frente a la revolución tecnológica deben redefinir sus posiciones tradicionales. La aplicación de la NRT que genera importantes transformaciones socioeconómicas modifica la naturaleza de la participación de las organizaciones sindicales. Estas deben tener incidencia en las modalidades de desarrollo económico, el perfil sectorial de la producción y su configuración territorial; igualmente deben participar en la negociación de las condiciones que implican las nuevas tecnologías que se reflejan en el proceso de trabajo, la flexibilización del mercado, las negociaciones colectivas y la política tecnológica del país. En este sentido, no deben constituirse en obstaculizadores del desarrollo tecnológico, sino en aprovechadores de las ventajas que ofrece y en observadores ctíticos de las dificultades que trae consigo.

"La reconversión productiva plantea a los sindicatos una seria disyuntiva: adoptar una posición puramente defensiva o una actitud ofensiva. Frente a medidas de reconversión que generalmente son adoptadas por la empresa sin consultar a los trabajadores, la actitud sindical defensiva se expresa como defensa <<pasiva〉> de las cléusulas del contrato colectivo. Pero esta actitud conduce inevitablemente a la derrota, porque los empresarios cuentan a su favor con el poderoso argumento del progreso técnico. La táctica defensiva finaliza con la división de los trabajadores... En cambio, una actitud sindical ofensiva consiste en anticiparse a las acciones de la empresa en materia de reconversión... [para ello se requiere] un cambio sustancial en la calidad del funcionamiento de la organización: este cambio se refiere a la necesidad de capacitar al sindicato para generar input cientifico y a la necesidad de reciclaje o desplazamiento de liderazgos sindicales y su sustitución por cuadros sindicales con formación técnica y cultural modema del trabajo... Se requiere un viraje ideológico del sindicalismo para que pueda competir programáticamente con las políticas noeliberales, ofreciendo nuevos caminos de modernización económica, productividad, integración solidaria entre los países latinoamericanos y apertura-integración en la economía global" (Godio, sf). 
Asistimos, pues, a una pérdida de identidad en los movimientos políticolaborales, ya que los sectores que por excelencia han sido defendidos y apoyados por posiciones de izquierda han sido los trabajadores -asalariados- 0 , mejor dicho, la clase proletaria u obrera, pero en la actualidad esta clase se encuentra en franco repliegue en cuanto a su importancia dentro de la Población Económicamente Activa (PEA). La incorporación creciente a la PEA de sectores cooperativistas, de informales, de pequeños propietarios agrícolas, del auge del sector servicios, dejan en desventaja numérica a los considerados estrictamente como obreros. Por otra parte, se observa un proceso acelerado de terciarización de los aparatos económicos. Asf́ tenemos que "Hoy, no más del 3 por ciento del precio de un chip semiconductor queda para los propietarios de materia prima y la energia, 5 por ciento para los dueños del equipo y las instalaciones, y 6 por ciento para la mano de obra rutinaria (en total suman cerca del 11 por ciento). Más del 85 por ciento es para servicios especializados de diseño e ingenierfa y para patentes y derechos de autor de descubrimiento, y buena parte de ello se queda en los Analistas Simbólicos" (Reich, 1993).

La CEPAL, al analizar las repercusiones que la NRT tendrá sobre las economfas de la región, parte del hecho de considerar a América Latina integrada a la economía internacional, y que ésta última se encuentra en un proceso de reestructuración de manera asombrosa y répida al indicar que "las actuales tendencias de la economia intemacional hacia la globalización y el acelerado cambio tecnológico, implican que las ventajas comparativas emanarán en forma creciente de aquellas adquiridas mediante un esfuerzo de modernización y penetración de mercados, en contraposición a aquellas derivadas de ventajas estáticas a base de recursos naturales o mano de obra barata, por ello es que las ventajas funcionales a los nuevos requerimientos para una adecuada inserción internacional son las ventajas competitivas creadas y no las tradicionales ventajas comparativas estáticas" (CEPAL, 1992).

Dentro del planeamiento de la CEPAL, elementos como competitividad e inserción internacional, progreso técnico y equidad deben recibir un tratamiento integrado, hay que verlos como un todo y no de manera separada. La competitividad internacional requiere de una transformación productiva hasada en la creciente difusión e incorporación del progreso técnico al proceso productivo, a su vez, el progreso técnico es el factor que posibilita el crecimiento con equidad y viabiliza la convergencia de la competitividad con la sustentabilidad ambiental.

La incorporación del progreso técnico al proceso productivo requiere del fortalecimiento de la infraestructura tecnológica, la base empresarial y la calidad de los recursos humanos; se requiere de políticas que faciliten el aprendizaje tecnológico y la articulación productiva y reconozcan el carácter sistémico de la 
competitividad. Para la CEPAL, ello no constituye una tarea fácil, por el contrario, es una tarea cuesta arriba derivada de la conjunción de varios hechos, entre los que destacan los siguientes: la crisis que lodavía se resiente de la década perdida; del relativo atraso tecnológico de la región; de la poca relevancia que tienen los campos de la ciencia, tecnologla e investigación en los programas oficiales y/o de las empresas; de las dificultades financieras externas (deuda, caída de los términos de intercambio, déficit comercial, etc.); de las dificultades que existen en los mercados de tecnología para poder tener acceso a ella, derivadas del proteccionismo tecnológico; de la insuficiencia del elemento humano que se requiere para impulsar, o en su caso aplicar, la NRT; de un cambio de apreciación sobre la función de las empresas transnacionales. Todo lo anterior debe insertarse en un proceso creciente de globalización económica; dicha inserción debe darse a partir de la productividad y no de desvalorizar aún más la fuerza de trabajo o a costa de un mayor deterioro de los recursos naturales o de polucionar el medio ambiente.

De acuerdo con la CEPAL, "la competitividad auténtica requiere no sólo de polfticas que modifiquen la estructura productiva sino de polfticas que induzcan una incorporación y difusión más rápida del progreso técnico, para ello hay que fortalecer la base empresarial, la infraestructura tecnologica, la articulación productiva en áreas bases como la información y telecomunicaciones, que eleven la competitividad sistémica, y de una fuerte inversión en recursos humanos" (CEPAL, 1992).

Para la CEPAL. uno de los fenómenos más importantes que opera es el de la globalización, entre lo que destaca: "La desregulación de los mercados financieros, sumada a las nuevas tecnologlas, ha contribuido a crear un inmenso mercado mundial de fondos e instrumentos financieros, que reportan volúmenes de transacciones muy superiores al del comercio de bienes... Las empresas Iransnacionales han adquirido cada vez mayor relevancia como protagonisfas fundamentales de la economía (y ellas esián en la capacidad de) variar las ventajas comparativas de un determinado pais en función de las decisiones tomadas por empresas sobre sus actividades productivas y de distribución... (con el agravante de) que la NRT está aminorando la ventaja comparativa tradicional de los paises en desarrollo, basada en mano de obra barata y materias primas naturales" (CEPAL, 1992). De ello se deduce que para los países subdesarrollados, su futuro dependerá de las nuevas tecnologías y, por qué no decirlo, de las empresas transnacionales, mismas que son las que tienen acceso a las innovaciones (tecnología de punta), a los mercados, los canales de comercialización, las vias de transporte, etc. O bien, pueden elegir un camino de autarquía y de defensa de una falsa soberanía, que muy poco podrá abonarles en las exigencias que las formas de producción impondrán de manera más drástica, que en el presente, los avances produclivos. 
"La globalización de la actividad económica tiende a una cierta uniformidad en cuanto a formulación y aplicación de las políticas, ya que cada país se convierte en un competidor para mercados finitos y recursos escasos. Por ello privilegiar las señales, fomentar la competitividad internacionah promover la capacidad empresarial y atraer la inversión directa se estón convirtiendo en elemenlas comunes de los esfuerzos que deben realizar las naciones para mejorar su inserción internacional" (CEPAL, 1992). Dentro de este ámbito se debe tener mucho cuidado, en el sentido de generar la inserción intemacional de manera eficiente y no espúrea. En todo caso, el futuro de las economías de América Latina no puede ni debe descansar en condiciones de producción que generen mayores dificultades socio-económicas, que se traduzcan en pobreza, analfabetismo, marginación, reducción de salarios reales, deterioro del medio ambiente, devaluación de las monedas, recorte del gasto social, etc. con la finalidad de mantener alguna ventaja competitiva para lograr la inserción internacional. En caso de seguir este camino, se estaria haciendo referencia a una competitividad espúrea y eftmera.. Por el contrario, lo que debe privilegiarse es la consecusión de competitividad genuina o auténtica, que se sustente en aumentos permanentes de productividad y que sean endógenos a las economías nacionales o regionales, con mayores niveles de equidad social en todo sentido, para que los frutos del progreso téenico se difundan hacia toda la sociedad. Esto requiere de una funcion activa de parte del Estado como ente transmisor y fomentador al respecto.

Además, las empresas Iransnacionales tienen asegurado un papel de primer orden en la nueva división intemacional del trabajo, mismo que debe ser tomado en cuenta por los paises subdesarrollados. Estos también deben tener presente de que a pesar de que se habla mucho de la liberalización de los mercados intemacionales, la realidad es un tanto aparente a este respecto, ya que lo que se está presentando en el comercio intemacional es la constitución de bloques económicos; as/ se tienen algunos que ya se encuentran en funcionamiento: el más desarrollado de todos es el Mercado Común Europeo que cuenta con 15 miembros y hay varios más en lista de espera; el Tratado de Libre Comercio de Norteamérica, el cual tiene la esperanza de que para el año 2005 se haya extendido por todo el continente.

"El esfuerzo de integrar agrupaciones o bloques de países podria interpretarse como una respuesta parcial y selectiva, entre paises con mayor afinidad de pollticas entre sh, a las exigencias institucionales del fenómeno de la giobalización... resulta más fácil armonizar políticas y adoptar normas y reglas comunes entre un número limitado de países relativamente homogéneos, que hacerlo entre los más de los cien países que pertenecen al GATT - hoy Organización Mundial de Comercio" (CEPAL, 1992).

“En la economla mundial ocurre una globalización de los mercados, caracterizada por una competencia creciente, que presiona hacia la búsqueda de tecno- 
loglas basadas en conocimientos cientlficos cuya incorporación al sistema productivo permite reducir costos, mejorar la calidad, ahorrar energía y materias primas escasas, a la par que aumentar la productividad de la fuerza de trabajo. El tercer mundo, tradicional productor de materias primas y productos con escaso valor agregado, se ve enfrentado a la ineludible inserción en la cconomía mundial con serias insuficiencias históricas. La política neoliberal ha demostrado desentenderse de tres problemas centrales que enfrentan los palses: las exigencias que plantea la competencia internacional en cuanto a capacidad competitiva para enfrentarla; la deteriorada situación social, es decir, la relación entre producción y distribución, y las fuertes cargas ambientales, o sea, la relación entre economía y ecología" (Martínez, 1994).

\section{Rlesgos y desafios}

Se puede afirmar, de acuerdo con diversos especialistas que tienen puntos coincidentes respecto al impacto que trae aparejada la NRT a nivel general, donde el proceso de globalización es uno de los mecanismos de penetración de sus repercusiones, ya que la aplicación de la NRT contiene enormes riesgos y desafios y que, en general, los países de América Latina se encuentran en una seria encrucijada, que se define por la siguiente disyuntiva: si rechazan su aplicación o si deciden implementarla, cualquiera que sea la decisión que se tome, implica una decisión difícil y de consecuencias serias, incluso, si deciden seguir un método que los combine.

Posiciones optimistas estiman que con algunos cambios América Latina podría acoplarse ventajosamente a la NRT. Esta posición es sostenida por el Fondo Monetario Intemacional, el Banco Mundial y el Banco Interamericano de Desarollo. Sus posiciones se pueden resumir de la siguiente manera: "Las oportunidades que para los países en desarrollo abren las nuevas tecnologías son en verdad múltiples. La mayor flexibilidad de las actividades productivas autoriza un nuevo enfoque del mercado interno, loda vez que resulta posible superar los tradicionales problemas de estrechez de mercado y generar configuraciones productivas más específicas y por tanto más adecuadas a las necesidades de estos países... Los nuevos desarrollos tecnológicos, al hacer más difusas las fronteras entre los principales sectores productivos (primario, secundario y terciario), permiten redefinir favorablemente la dinámica de los procesos de industrialización a través de la constitución de complejos productivos a partir de recursos naturales" (Ominani, 1992).

Existen posiciones intermedias que indican que la NRT puede ser absorbida e incorporada parcial y relativamente por los países subdesarrollados, pero para ello deben realizarse de manera previa adecuaciones a las formaciones sociales. Esta es la posición de la CEPAL. Parten del presupuesto de que las nuevas tecnologías estarán disponibles. En todo caso, desde esta situación se debe dejar 
en claro que el eje de la propuesta va hacia afuera en materia de exportaciones, y viene desde fuera en materia de tecnologia y flujos financieros. Si se lograra un adecuado manejo de esta situación, ello podrí conducir a un ensanchamiento del mercado interno, lo cual mejoraria la distribución del ingreso y a la vez la productividad. Hay que tomar en cuenta que las readecuaciones que se deben impulsar se tienen que desarrollar durante un largo proceso; tstas no pueden ser adquiridas de la nocbe a la mañana. Exigen crearse a partir de profundas y prolongadas transformaciones internas a las que generalmente no están dispuestos quienes favorecen esta tendencia; en todo caso, las transformaciones podrían durar toda una generación.

Otras posiciones rechazan todo vínculo con la NRT ya que la consideran atentatoria a los valores culturales de la mayoría de los países subdesarroliados, o bien, indican que con su aplicación las actuales formas de vida, y la humana no es la excepción, pueden sufrir cambios genéticos impredecibles. Esta misma posición también considera los cambios que puede sufrir el ya tan deteriorado medio ambiente, que puede llevarlo a un punto sin retomo en la degradación ambiental.

En lo que debe existir un mayor nivel de coincidencias es en cuanto a que el futuro de las economías de América Latina no puede descansar en condiciones que impliquen competitividad espúrea y efimero. Debe privilegiarse la consecusión de competitividad genuina o auténtica.

Las posiciones que tienen un punto de vista negativo sobre la NRT, apuntan a que los únicos países que se verán fivorecidos son los que van a la cabeza en lo que a tecnología de punta se refiere (Estados Unidos, Japón y la CEE), mientras que las regiones atrasadas soblo tendrán acceso a tecnologia de segunda generación, a aquella que sea considerada contaminante o riesgosa; en lodo caso, el control continuara en el centro. Dificilmente los países centrales dejarian el control de sus avances tecnológicos, máxime si en los países atrasados no existe el personal idóneo para su puesta en marcha o su perfeccionamiento. Si se toma en cuenta que "muchas industrias de los paises pobres que nacieron (bajo el impulso de la sustitución de importaciones), con frecuencia, viejas desde el punto de vista técnico, son hoy definitivamente obsoletas" (Thai-Hop, 1995).

Adernás, hay quienes ven infranqueable la diferenciación entre el mundo desarrollado y el atrasado o relegado, dentro de estas posiciones está la siguiente: "La mayor parte de la tecnologia que se transfiere al Tercer Mundo consiste en conjuntos de técnicas y métodos comunicados por las corporaciones multinacionales, inevitablemente adaptadas al sistema de consumo el norte del mundo. Lo que unido a la complejidad tecnica y a la exigencia de investigación fundamental que acompaña al desartollo del sector, aspectos en los que los países de la periferia ni pueden ni remotamente pretender acercarse a los del centro, reservan a estos papeles residuales, como fuente de mano de obra barata o como 
patética demanda final... La división internacional del trabajo queda redisefiada entre los mismos capitalistas... Lo diferencia tecnológica nunca podra salvarse. Los gastos que representa iniciarse en el camino del desarrollo tecnologico para ponerse a la altura de los líderes mundiales estarfan fuera del alcance de prácticamente todas las naciones" (Ovejero, 1989).

De nueva cuenta, lo que se tendrá es un tremendo auge de las empresas transnacionales, sólo que en esta ocasión, ante la debilidad de los Estados nacionales por la aplicación de politicas neoliberales, sus posibilidades para ejercer algún tipo de control se verán tremendamente disminuidas, respecto de lo que fue durante el proceso de sustitución de importaciones. En el interior de los países subdesarrollados, la NRT generará verdaderos enclaves y el grosor de la población continuará alejada de ver los frutos a su favor.

\section{Implicactones}

Cada uno de los componentes de la NRT presenta aspectos positivos y negativos. A continuación se presentan algunas consideraciones al respecto que han sido extraldas del artículo de Schults.

\section{(a) Sobre la microelectrónica.}

Aspectos positivos: mejores pronósticos del clima, anticipación de riesgos naturales y catástrofes; reestructuración de la organización de los servicios públicos para hacerlos más efectivos; descentralización eficiente de la información para la toma de decisiones. Poner al alcance de los productores redes de información sobre precios, mercados, tipos de cambio, avances técnicos, etc. Mejorar el uso del agua y de fertilizantes, y el manejo de agrosistemas complejos por medio de modelos y sisternas computarizados. Explotación de recursos naturales en zonas lejanas e inhóspitas a traves del uso de las telecomunicaciones, la robólica y la automatización, etc. Mejorar las venntajas comparativas de las ciudades pequeñas y de las empresas medianas y pequeñas.

Aspectos negativos: disminución de los niveles de empleo y reducción de la localización metropolitana del mismo. El peligro que entraña la centralización o el monopolio de la información. Monopolización de las comunicaciones por satélite y de la prospección de los recursos naturales. Incorporación más estrecha y dependiente de la producción de pequeña escala a los ciclos y manejos del gran capital. Cambios en las ventajas comparativas internacionales, en contra de los recursos intensivos de fuerza de trabajo no calificada y de recursos naturales. Marginación, desplazamiento o subordinación absoluta de los segmentos de los recursos productivos que no puedan acceder a las nuevas tecnologfas. 


\section{(b) La biotecnologin.}

Aspectos positivos: reciclaje de nutrientes y desechos. Grandes avances en la producción de alimentos y en las condiciones sanitarias y nutricionales de la población, asi como en la cura de enfermedades. Valoración de nuevos recursos naturales renovables. Nuevas formas de solución a los limitantes naturales de la producción animal y vegetal, a partir del desarrollo de nuevas variedades resistentes a condiciones ambientales extremas. Nuevas técnicas de tratamiento y conservación de los productos agricoles. Nuevo impulso para el control biológico de pestes y patógenos en el sector agropecuario. Factibilidad de aumentar la diversidad de la produccióa agropecunria mediante la recucción del predominio de la monoproducción. Revalorinción de las tecnologias de producción de energfa de biomasa. Desconcentreción do los servicios urbanos (salud, energía, tntamiento de residuos, etc.). Desnrrollo de una agricultura urbena y periurbana competitiva.

Aspectos negativos: cambios significativos en las ventajas comparativas a nivel nacional e intemacional, tales como la perdida de ventaja relativa de los suelos fértiles. Concentración de su uso para el desarrollo de la agricultura de exportación a costa de la producción alimentaria para el mercado intemo. Aplicación a los segmentos productivos modernos més que a los tradicionales. Surgimiento de problemas sociales y tícos nuevos asociados al uso de la biotecnologla en seres humanos (manipulación genética). Las condiciones tecnicas de producción se alejarán cada vez más de la capacided de control del productor (semillas especiales, insumos importados, etc.). Apropiación y monopolización del germoplasma originario de la región por parte de las empresas transnacionales (patentes, royalties, prohibiciones de uso, etc.). Explotación selectiva y expoliadora de ecosistemas para extraer sustancias o componentes valiosos para la producción biotecnológica (área de fármacos). Nuevos impactos ecológicos negativos, especialmente por la síntesis e introducción en el ambiente de nuevas sustancias y formas de vida. Asimismo, la manipulación genética ejercerá efectos imprevisibles a largo plazo. Aumento en la vulnerabilidad de variedades debido a la reducción en la variabilidad genética (clonación). Impacto diferencial en productores (modemos contra (radicionales) según su acceso a la biotecnología.

\section{(c) Los nuevos materiales.}

Aspectos positivos: nuevas oportunidades de reciclaje de residuos. Abaratamiento en los coslos de cobertura de las necesidades básicas no alimentarias, particularmente en vivienda y transporte. Combinación de materiales tradicionales locales con nuevos materiales. Cambios en los sistemas de transporte.

Aspectos negativos: El cambio en la competitividad entre materiales naturales y sintéticos. Pérdida de las ventajas relativas de los yacimientos minerales estratégicos, en especial, cobre, níquel, cromo, cobalto, manganeso. La inestabi- 
lidad que surgiría en los términos de intercambio si desaparecieran industrias enteras y surgieran otras totalmente nuevas. Contaminación por nuevos tipos de residuos materiales, biodegradables y otros que no lo sean. Utilización de materiales no tradicionales para la construcción que desplazarian la demanda de tejas, arcilla, ladrillos, paja y otros bienes tradicionales. Relocalización de industrias en dirección a los centros urbanos donde se encuentra la fuerza de trabajo especializada. Aparición de nuevas industrias contaminantes.

Como corolario de eslos aspectos positivos y negativos, donde no se encuenuran todos ni necessriamente los más importantes, no se puede hacer un balance que nos indique que los aspectos positivos pesan más que los negativos o viceversa, y que a partir de esa consideracion se pueda inferir que son en esencia positivos o negativos. Esto no se puede realizar ya que los componentes de la NRT tienen un carácter sistémico integrado a una determinada red de relaciones sociales, que hará uso de ella según sea la distribución del poder y de los intereses de las fracciones hegemónicas del capilal. Lo que fríamente, en el escritorio y el papel, podrían ser aspectos positivos o negativos se convierten en elementos para reforzar el poder establecido en nuestros países, donde no se posee ni se controla esa tecnología.

Por lo tanto, si bien las nuevas tecnologías podrfan tener efectos positivos importantes para las economías atrasadas, dada la estructure del poder, su uso estara dirigido fundamentalmente a mantener el orden establecido. En general, la tecnología no es buena o mala en sí, todo depende de su uso, y éste está en función de quienes la poseen, controlan, aplican y usufructan.

Las nuevas tecnologlas vienen a ser como una gran espada de Damocles que pende sobre América Latina. Cualquier decisión que lome necesariamente traerá grandes repercusiones, es decir, que ya sea que se suba al tren, aunque en el último vagón de la NRT, o bien que lo deje pasar y se quede esperando el próximo (otra RT, es decir, la próxima) para subirse en los primeros vagones si es que logra comprar un boleto de primera clase; siluación que dificilmente podría darse. Cualquier resolución al respecto no podrá considerarse inocua, sino que afeclará todo el entomo socioeconómico.

En todo caso, un elemento siempre hay que tenerlo presente: resulta contrario a la lógica del desarrollo humano el negar la modemidad -los adelantos tecnológicos. Tarde o temprano habrá que incorporarlos y para ello hay que trabajar con visión de futuro y el ánimo expreso de llegar con ventaja.

Las nuevas tecnologías necesariamente modificarán de manera profunda la inserción de América Lalina en el mercado mundial. "Ante la automatización programable, la mano de obra barata sólo continuará siendo un factor de importancia en la competencia internacional si se relaciona con uno o más de los siguientes elementos del entomo del proceso productivo: (a) si hay cercanía del 
mercado final; (b) si hay presencis de proveedores locales de insumo; (c) si posec una dotación de recursos humanos capacitados en función de la calidad del producto y proceso; (d) si la organización laboral está dispuesta a la flexibilidad en el manejo del mercado laboral, en lo que se refiere a contratación y jomada; (e) si existe suficiente mano de obra calificada a nivel técnico y de ingenieros, y (f) si posee disponibilidad de infraestructura de teleinformática" (CIOSL/ORT/CISLOIT, 1989). Esto implica que la abundante mano de obra de que dispone América Latina tendrá relevancia únicamente si cuenta con lo anterior, de lo contrario, le corresponde, si mejor le va, dedicarla a la maquila sencilla, ante todo la relacionada con el vestuario, por lo que no se augura un futuro alagüeño.

\section{Los retos}

Diversas instituciones como la CEPAL, la Universidad de la Naciones Unidas (UNU), la Asociación Latinoamericana de Organizaciones de Promoción (ALOP), la Organización Regional Interamericana del Trabajo (ORIT), el Sistema Económico Latinoamericano (SELA), etc. y diversos autores latinoamericanos o conocedores de la situación coinciden en señalar que América Latina y todos los paises del Tercer Mundo, exportadores de bienes primarios, se encuentran ante un gran dilema producto de los avances en los procesos poductivos generados por los avances tecnológicos de la NRT. Los notables avances registrados en el campo de la producción y las nuevas posibilidades de como producir que trae consigo la NRT, ponen en peligro el futuro del Tercer Mundo. Gracias a la microelectrónica (robotización, control de inventarios, máquinas de control numérico, etc.), la productividad se ha elevado de manera increíble, situación que ha conducido a un tremendo abaratamiento de los costos de producción. Con la biotecnología, muchos productos que antes únicamente podlan producirse de manera narural, en la actualidad pueden ser producidos en el laboratorio o mejorar su rendimiento de manera artificial.

En Estados Unidos, más del $\mathbf{3 0}$ por ciento de la mantequilla que en estos momentos se consume proviene de la alteración biotecnológica que se hace de la margarina vegetal, cuyo contenido es similar al de la mantequilla de origen animal, lo cual se realiza mediante procedimientos técnicos en el laboratorio. Igualmente, los nuevos materiales están sustituyendo muchos minerales que eran objeto de mercado internacional. Así, el cobre está siendo sustituido por la fibra optica que, además de ser mucho más barata, es mejor conductora; también se encuentran en producción motores de arcillas mejoradas, etc. La cita siguiente es reveladora a este respecto: "En el futuro, la ventaje competitiva duradera dependerá mis de las nuevas tecnologias de procesos y menos de las nuevas tecnologías de productos. Las nuevas industrias del futuro, por ejemplo, la biotecnología, dependerán de la capacidad cercbral. Las ventajas comparativas del trabajo humano reemplazan a la ventaja comparativa de la Madre Naturaleza -la posesión de recursos naturales-o de la historia -recursos de capital' (Thurow, 1992). 
O bien, afirmar que "Evaluando los elementos, tanto los que disminuyen el papel del costo de la mano de obra en la competencia internacional como los que lo sostienen, llegamos a concluir que la mano de obra barata es un factor estático en la ventajas comparativas y, como tal, es rebasado por los avances tecnológicos aplicados en los procesos productivos" (Mertens, 1991).

Muchos de los resultados concretos que ya se están produciendo o se pueden producir o que en el futuro se pueden descubrir, como resultado concreto de la aplicación en el proceso productivo de las NRT, vienen a competir directamente con las tradicionales ventajas comparativas naturales de que se han ufanado las conomlas del Tercer Mundo; en esa competencia la ventaja la tiene la NRT.

Los países productores de materias primas agrícolas ya se encuentran experimentando las consecuencias de la NRT, así tenemos los ejemplos siguientes: "el azícar de cafía está siendo sustituido por jarabe fructuoso de maíz. En Estados Unidos más de 34 fábricas de refresco están usando ese sustituto de la caña. Se calcula que la Coca Cola y la Pepsi están ahorrando anualmente unos 90 millones de dólares al usar jarabe, que resulta 25 a 30 por ciento más barato que el azícar. Otros edulcorantes, como el aspartamo, son desarrollados sintéticamente desde el petróleo mediante el uso de la biotecnologia. (Por otra parte) ya existe sustitución flexible entre las diferentes materias primas de aceite vegetal utilizando biotecnologla... Otros productos agrícolas también tienen sustitutos, como la vainilla y el pyrethrum -que es materia prima para pesticidas-, la soya y la harina de pescado también se encuentran con sustitutos... Se está sustituyendo el cobre por fibra óptica, nuevos polímeros sustituyen a aceros, la cerámica a minerales... Se terminó el período en que los procesos productivos tenían una sola forma de llevarse a cabo, las materias primas se vuelven intercambiables y el campesino de cacao está compitiendo con el campesino de aceite de coco o con la plantación de aceite de paima" (Mertens, 1991).

Surge el dilema, ¿que hacer, de parte del Tercer Mundo, ante el reto que les impone la NRT? La respuesta no es sencilla, muchos aspectos tendrán que cambiar, como la división internacional del trabajo, la función del Estado, las relaciones obrero-empleador (hasta en este punto se siente ya el cambio, como se puede apreciar, la palabra patrono se ha cambiado por la de empleador, incluso, en la terminologla que utiliza la OIT).

De una situación se debe tener claridad desde el principio, y es que ningún país del Tercer Mundo, incluida América Latina, se encuentra en capacidad de competir tecnológicamente con los avances de la NRT. A manera de ejemplo, "en el inicio de las nuevas tecnologías, las innovaciones se dieron en pequeñas empresas, fundadas muchas veces por ingenieros que trabajaban en compañlas como la IBM, Foirchild, $A T T$, etc. Pero, en la actualidad, las innovaciones en el campo de las nuevas tecnologías requieren de mucha inversión, primero en investigación y después en maquinaria y equipo para producirlas. Para damos una 
idea, en 1972 se requirió de una mínima inversión de bienes de capital, de dos millones de dólares, para producir un circuito integrado; en 1982 se necesitó invertir 60 millones. Para el desarrollo del megachip, las empresas transnacionales Philips y Siemens están ocupando a mil ingenieros y técnicos durante un período de cuatro afios" (Mertens, 1991).

La tecnología de punta se está generando en aquellas regiones que cuentan con los requerimientos necesarios para ello, como lo es una importante base de conocimiento cientifico-practico, en otras palabras, capital humano en proporciones importantes; también se requiere de un importante y decidido programa de ciencia y tecnologla (investigación y desarrollo), donde la función del sector público es primordial. Como todo ello requiere de enormes gastos, se bace indispensable contar con suficientes recursos para hacer andar la producción de ciencia y tecnología que permita el desarrollo de tecnología de punta.

Como ya se indiob, ningún pals del Tercer Mundo se encuentra en la competencia tecnológica "se cree que las siete industrias básicas para las próximas décadas serán: la microelectrónica, la biotecnología, las industrias de los nuevos materiales, la aviación civil, las telecomunicaciones, los autómatas más las máquinas herramientas, y los ordenadores más el software. Todas son industrias que dependen de la capacidad cerebral. Todas podrán instalarse en cualquier lugar del planeta. Donde se instalen depende de quiénes puedan organizar la capacidad cerebral para aprovecharlas. En el siglo que se avecina, la ventaja comparativa será creación humana" (Thurow, 1992). Además, en cada una de estas industrias existe una clara concentración de la producción en pocas empresas, a lo sumo cinco transnacionales.

Dentro de esta competencia tecnologica que se está operando, se dice que incluso Estados Unidos está perdiendo la batalla respecto a Japón y Alemania. Al comparar los gastos de las empresas en investigación y desarrollo se llega a la conclusión siguiente: "las firmas norteamericanas gastan dos tercios de su dinero en nuevos productos y un tercio en nuevos procesos. Los japoneses hacen exactamente lo contrario, un tercio en nuevos productos, dos tercios en nuevos procesos... Mientras los norteamericanos concentraban la atención en las tecnologlas de los productos, Japón y Alemania se concentraban en las tecnologías de los procesos... [al comparar lo que ha acontecido con algunos de los más importantes nuevos productos que se han lanzado al mercado internacional a partir de 1970, como son:] la videocámara y el grabador, el fax y el reproductor de discos compactos. Los norteamericanos inventaron la videocámara y el grabador y el fax; los holandeses el reproductor de discos compactos. Pero en términos de las ventas, el empleo y los beneficios, los tres se han convertido en productos japoneses... Moraleja: Las que pueden fabricar más barato un producto pueden arrebatarselo al inventor" (Thurow, 1992). 
Al ver los resultados del mercado de autos en Estados Unidos, se pueden observar las tendencias siguientes: "los fabricantes europeos han sido expulsados o están perdiendo rápidamente su participación, han sido desplazados por los japoneses, quienes han proporcionado un knockout técnico... Los japoneses pueden montar un automóvil de lujo con sólo una cuarta parte de la fuerza de trabajo requerida en Europa. Pueden poner en producción modelos nuevos con más rapidez y sus vehículos exhiben menos defectos... Los japoneses están creando más capacidad de producción en Estados Unidos de la que posiblemente pueden utilizar en ese pafs" (Thurow, 1992).

Para complementar lo anterior, baste indicar que "Los déficits comerciales (de Estados Unidos) con Japón, y con nadie más, han estallado en el área de alta tecnología... Ningún pars industrial tiene un excedente comercial con Japón en el área de los productos manufacturados. Los más grandes exportadores del mundo, los alemanes, no pueden competir con éxito en el mercado japonés... (Como apoyo a lo anterior, lo siguiente:) En Estados Unidos, los gasios en investigación y desarrollo disminuyen durante los períodos de recesión económica y aumentan en los períodos de auge. En Europa y Japón no sucede lo mismo. Para una empresa norteamericana, la reducción de la investigación y el desarrollo es una técnica para mantener los beneficios durante un período de disminución de las ventas. En Europa y Japón no se reduce la investigación y el desarroIlo. pues se la considera la fuente de la capacidad competitiva a largo plazo" (Thurow, 1992).

Tal como ya se dijo, la disputa por el avance tecnológico se está dando especialmente entre tres regiones -Estados Unidos, Japón y Alemania (CEE)-. que son los que han estado a la cabeza de los descubrimientos científicos, al menos después de la segunda guerra; la ex URSS queda excluida ya que debido a los sucesos posteriores a 1989 quedó relegada en lo que a avances científicos se refiere. Esto fue ocasionado por diversas razones, entre ellas, a que su desamollo científico, previo a 1989, estuvo orientado ante todo al campo estratégicomilitar y, en menor medida, al campo económico. También indica que desde 1989 ha experimentado una tremenda fuga de cerebros hacia occidente ocasionada, en muchos casos, por la grave crisis económica y política por la que atraviesan las sociedades que vivieron en el socialismo real.

En todo caso, los países del Tercer Mundo, en general, y América Latina, en particular, no cuentan con los requerimientos indispensables para poder entrar en la disputa tecnológica que implica la NRT. Esto se debe a varias razones, entre las que destacan: una insuficiencia de masa crítica en el campo tecnológico, ocasionada por la fuga de cerebros y una deficiencia histórica en este campo; una total deficiencia en materia de Ciencia y Tecnologfa, que implica muy poco. si es que ningún, avance en Investigación y Desarrollo, esto se aplica tanto a la iniciativa privada como al sector público. 


\section{Papel de América Latina}

América Latina se encuentra $\rightarrow$ mediedos de la déada de los noventa - en una situación difícil. Diversos factores indican lo complejo de su situación: durante los ochenta, llamada la decada perdida, el ingreso per cápita cayó de manera alarmante, se convirtió en una exportadore neta de capilales. La aplicación de políticas de ajuste condujo a una mayor presión sobre los sectores más desprotegidos - cocialmente hablando-; amplios sectores se debaten en la pobreza. El promedio regional es de $\mathbf{4 6}$ por ciento y en algunos países sobrepasa el 70 por cienlo.

Dentro de este ámbito no todo es negativo, ya que se han dado algunos pasos importantes. Asl se tiene que en la práctica han desaparecido los regímenes antidemocráticos - las llamadas dictaduras militares - la evolución económica ha pasado a ser de signo positivo, el ingreso per capita experimenta crecimientos, la crisis de la deuda presenta una cendencia a ser menos relevante.

Para esta parte del trabajo se tomaron ideas del planteamiento que se hace en un estudio multidisciplinario titulado "Las nuevas tecnologías y el futuro de América Latina. Riesgo y oportunidad", de Amflear Herrera, et. al., realizado por encargo de la Universidad de las Naciones Unidas (UNA). El estudio parte del hecho de que la actual crisis mundial se manifiesta en múltiples ámbitos y que se trata de una crisis que no tiene precedentes. Por primera vez en la historia la humanidad puede ser destruida por sus propias acciones. De continuarse la actual trayectoria de desarrollo que se viene siguiendo desde la revolución industrial, el mundo no será viable, en otras palabras, el estudio tiene una concepción apocalíptica que se puede resumir de la manera siguiente: o se modifica la tendencia o el fin de la humanidad se ocerca de manera acelerada e implacable.

Aunque la crisis sea vista de manera catastrófica, el futuro no necesariamente tiene que seguir por el mismo camino, ya que por vez primera en la historia, la humanidad posee el conocimiento necesario para resolver todos los problemas relacionados con las bases materiales de la vida. Es decir, que gracias a la NRT se tiene la posibilidad térica y material de asegurar a cada ser humano un nivel de vida que no sólo lo provea de sus necesidades bésicas materiales, sino que le asegure también una plena y activa incorporación a su cultura.

Todo ello se produce dentro de lo que se podría denominar 'civilización mundial', que implica no sólo la globalización económica sino también las así llamadas 'interferencias de gobernabilidad'. Estas implican la mundialidad de muchos problemas, es decir, que las decisiones soberanas que un determinado gobiemo ejerza sobre su territorio pueden tener repercusiones más allá de sus fronteras, por ejemplo, "Las fronteras y la soberanía de los Estados no detienen la contaminación radiactiva, ni la lluvia ácida ni la creciente polución de los mares y los ríos, ni tampoco ningún gobiemo, individualmente, puede hacerse 
cargo de la solución de esta clase de problemas. Frente a un peligro inmediato, se ha comenzado a profundizar en fórmulas de cooperación internacional... Hay otros peligros para el medio ambiente, a más largo plazo, cuya solución implicará en mayor grado, la revisión de la intangibilidad de la soberanfa. Por ejemplo: el riesgo del aumento de la temperatura del planeta puede exigir la imposición de una enérgica solidaridad en los palses más desarrollados para controlar las emisiones de gas carbonico... Señalar culpabilidades individuales no resolverfa esta clase de problemas; lo que queremos destacar es que el mundo puede encontrarse ante situaciones sin salida si la soberanfa del Estado, de cualquier Estado, continúa considerándose intocable. Tímidamente los gobiemos han comenzado a pronunciarse colectivamente en este sentido y a afimar, por fin, que "nuestro mundo es el planeta»" (Arbos y Giner, 1993).

Los elementos más importantes de la actual crisis mundial, es que las premisas del modernismo basadas en que gracias al desarrollo cientfico los problemas de insuficiencias para la humanidad serían cosa del antiguo régimen, pero la realidad ha demostrado una seria contradiccion; un minimo porcentaje de la humanidad ha logrado alcanzar niveles de satisfacción muy altos pero, en contraposición, la mayorla de la población mundial, dos tercios, continúa debatiéndose en la miseria, es decir, que los logros del desarrollo científico no les ha llegado. En la actualidad se puede observar que uno de los resultados del paradigma tecnoeconómico aplicado es que la brecha que separa a los estratos poblacionales de alto consumo con aquellos estratos de consumo insuficiente, se va ensanchando día con día.

Para superar esta dicotomfa mundial, misma que se impone no sólo por cuestiones ético morales, sino también por el hecho que de continuar con esta tendencia el futuro de la humanidad se encontrarla en entredicho, es que se debe hacer un alto y aprovechar las ventajas que ofrece la NRT. Para ello, la UNU define las que deberlan ser las características básicas de las sociedades del fuluro. Estas son las siguientes: (a) igualitaria en el acceso a bienes y servicios. $(b)$ Participativa, ya que lodos los miembros tienen el derecho a participar en las decisiones sociales en todos los niveles. (c) Autónoma (no autárquica), esto significa la capacidad de tomar decisiones basadas en sus propias aspiraciones y posibilidades. (d) Que disponga de suficiente tiempo libre para dedicarlo a actividades creativas. Las nuevas tecnologías permiten eliminar poco a poco el trabajo rutinario enajenante. El objetivo final será terminar con la presente división social compulsatoria del trabajo. (e) Intrínsecamente compatible con su medio ambiente físico. En otras palabras, la compatibilidad deberá basarse no en medidas correctivas tomadas a posteriori, sino en la misma naturaleza del estilo de desarrollo.

Para la totalidad de los países de América Latina, el reto que les impone el impulsar una estrategia definida con base en las caracteristicas anteriores, debe 
iniciar por buscar potenciar al máximo sus capacidades de manera integnal, ya que la rogion vista de manere global posee un patrimonio impresionante de rocursos anturiles que la colocan como a una de las regiones del mundo con mayor capacidad de desarrollo, pero su aprovechamiento depende de una efectiva integración económica y polftica de los palses que la componen

La integración econónica y política representa la única opción para que América Latina pueda ser un interlocutor válido, en une coonomía mundial cada vez mós competitiva y donde predominen los grendes bloques económicos. A esto hay que agregarle la necesidad de hacerle frente a los grandes desaffos tecnológicos, lo cual exige la formación de grandes espacios económicos para encarar los enormes esfuerzos de investigación requeridos por el desarrollo de las nuevas tecnologias.

Para América Latina, el hecho de transformar su estilo de desarrollo, de acoplarse a las nuevas modalidades, le implica tomar en cuenta su inserción en el mercado intemacional y su capacidad de manipulación sobre las variables que inciden al respecto. En ello intervienen, de una manera dialéctica, variables tanto extemas como internas. Dentro de las variables extemas, las más importantes son:

E.(1) La relación que existe entre dependencia y autonomía.

E.(2) La relación entre la crisis económica mundial y las posibilidades de una recuperación de la economía mundial.

Las principales variables internas que se deben considerar son:

L(1) La disyuntiva entre el pacto social concentrador y un pacto social democrático.

L(2) Una baja cooperación regional o una fuerte cooperación latinoamericana.

I.(3) Seguir un estilo de desarrollo depredador o un estilo de desarrollo ambientalmente sustentable.

Todas estas variables se encuentran interactuando y unas tienen más peso que otras. Asl, la transformación del pacto social l.(1) es un prerrequisito básico para que ocurran cambios en las otras variables. Pero no es indispensable para que courran cambios positivos en todas las variables reslantes, ya que resulta ser insuficiente para sacar a la economía mundial de la crisis E.(2). Aunque es coadyuvante importante para modificar la situación de dependencia de la región E.(1), y puede permitir que transite hacia un mayor nivel de autonomla, también podría ayudar a romper el nivel de aislamiento que existe entre los países latinaamericanos

El hecho de modificar de manera positiva el estilo de desarrollo depredador I.(3), no necesariamente deriva de superar el modelo concentrador, ya que una 
sociedad más justa puede continuar siendo depredadora del medio ambiente, tal como sucedió durante el socialismo real. De prolongarse la crisis económica mundial E.(2), ello no redundarfa de manera positiva para la consolidación del pacto democtático.

El escenario deseable que posibilite una transformación radical de la situación en América Latina, de acuerdo con las consideraciones que hace la UNU, implica una nueva alianza entre los movimientos populares, clases medias y burguesia ilustrada. El pacto que surja deberá tener como meta principal integrar al desarrollo económico la parte mayoritaria de la población que, en la actualidad, se encuentra marginada.

El nuevo pacto requiere de los siguientes elementos:

- Autonomfa. Debe implicar una revisión radical de las actuales relaciones que se tienen con los países centrales, en la búsqueda de mayor cooperación y trato igualitario entre el norte y el sur; al mismo tiempo debe buscarse un mayor nivel de cooperación latinoamericana.

- Un pacto social democrático que no es incompalible con una economa de libre empresa, ya que hasta los empresarios privados estarian interesados en profundizar el mercado interno, situación que les redundaria en una ampliación del proceso de acumulación.

- Reformas estructurales, patrimoniales dentro de la propuesta de la UNU, que impliquen una mejor distribución del patrimonio físico. Entre ellas destacan la reforma agraria y la reforma urbana que busquen adecuar el uso del suelo a las necesidades sociales de la población urbana. También es necesario realizar reformas que impliquen la redistribución del ingreso, ya sea a través de una elevación de la masa salarial en relación con el ingreso del capital, o bien, mediante un incremento del salario indirecto a través de una mejor provisión de servicios sociales a la población, que sean proporcionados a través de políticas públicas.

La propuesta de reforma agraria difiere de las propuestas que se hicieran en los años posteriores a la Segunda Guẹrra Mundial -que tenfan un significado más revolucionario que técnico-, ya que implica el acceso de la población pobre a la tierra con el objetivo de incrementar la producción de alimentos, siempre y cuando ella se dé en tierras improductivas, poco utilizadas u orientadas a cultivos de exportación. Con ello se estarla en posibilidades de generar un excedente agrícola que incrementarfa los niveles de ingreso en el área rural, siempre y cuando se aprovechen las ventajas que tiene la NRT para el agro.

La reforma urbana debe idearse sobre la base de reducir el alto nivel de especulación que existe sobre los terrenos urbanos. Debe comprender una zonificación de las diversas actividades urbanas, implementarse un sistema de trans- 
porte colectivo eficaz y construirse viviendas e infraestructura de saneamiento para la población necesitada.

En cuanto a la elevación de los ingresos reales y una mejor distribución de los mismos, no basta sólo con llevar a cabo las reformas patrimoniales propuestas, sino que resulta indispensable elevar el nivel de productividad de la población trabajadora mediante la obtención de empleo. Todo ello requiere de la reactivación económica.

Para incrementar el gasto público social, que pase del 10 por ciento sobre el PTB, que en estos momentos se tiene como promedio en los países de América Latina, a por lo menos 15 por ciento, se requiere, aparte de la reactivación económica, de un mayor papel del Estado en cuanto a presión fiscal lo que implica incrementar la relación impuestos/PTB.

Se debe tomar en cuenta que el modelo propuesto por la UNU no implica un excesivo intervencionismo estatal, ya que puede conducir a resultados inadecuados, tal como sucedió durante la etapa de sustitución de importaciones y a la que critica de la siguiente manera: "Tal vez la mayor distorsión de la industrialización latinoamericana fue provocada por el exceso de proleccionismo, el cual no estuvo acompañado de una política coherente de capacitación tecnológica local. El modelo seguido, de sustitución de importaciones, generó industrias con tecnologla poco dinámica en la medida en que las fronteras aduaneras y una serie de olras restricciones proteglan de manera indefinida la inefíciencia... En realjdad, el proteccionismo por tiempo ilimitado, sin una polf́ica de ciencia y tecnolog fa e industrial coherente de formación de una capacidad interna, permitió que proliferasen industrias con mercados demasiado pequeños, cuya productividad era muy baja y, peor aún, con escaso dinamismo tecnológico".

La estrategia propuesta es clara al indicar que no debe recurtir "en exceso al intervencionismo estatal. De hecho, las transformaciones de la estructura productiva que deberán ocurrir por fuerza para que las necesidades básicas de la población marginada sean satisfechas, derivan en esencia de los cambios en la distribución del ingreso... El Estado tendrá una importancia fundamental en varios niveles: deberá fijar reglas claras para el funcionamiento de las empresas multinacionales; deberá continuar monopolizando algunas actividades asociadas con la infraestructura económica tales como la energía, comunicaciones y transporte, aunque puede haber participación privada en estos rubros, pero estará sometide el interés público; asimismo deberá poseer un cierto grado de dirección para encuadrar y fomentar sectores punta, permitiendo que mediante una protección temporal puedan constituirse en empresas nacionales, con efectiva capacitación tecnológica; por último, el Estado deberá ejercer una efectiva acción en el ámbito de la fiscalización y normalización de la actividad productiva, para propiciar una mejora de la calidad y del nivel tecnológico de los bienes y servicios ofrecidos en los países latinoamericanos". 
Para compatibilizar lo anterior se hace necesario utilizar los siguientes instrumentos de la política económica: (a) La integración latinoamericana. (b) Canalizar una parte de los recursos financieros del Estado hacia los sectores que constituyan un punto de estrangulación para el crecimiento económico, como la energla, los transportes, la agricultura, las comunicaciones y la industria básica. (c) Reducir el grado de dependencia tecnológica. (d) Encoadrar la industrialización de los sectores de punta y proteger las industrias nacionales. (e) Aumentar la eficiencia de los procesos productivos, mediante la reducción en forma planificada de todo tipo de subsidio, incentivo, protección tarifaria, etc. Reducir poco a poco y de forma planificada las barreras aduaneras dentro de la región. (f) Fomentar la difusión de las nuevas tecnologías en el aparato productivo. (g) Fomentar una política de ciencia y tecnologfa a nivel regional.

\section{Nuevo Papel Propuesto por la CEPAL}

El modelo desarrollista que propuso la CEPAL, para lograr revertir el modelo de 'desarrollo hacia fuera' por uno que buscara el 'desarrollo hacia adentro', en el cual se debería privilegiar la integración económica, las reformas estructurales, la industrialización sobre la base del proteccionismo, en fin buscar el camino del modernismo.

El enfoque propuesto por Prebish partió del modelo centro-periferia, que indica que el intercambio comercial entre países industrializados y países en vías de desarrollo no beneficia a ambos grupos por igual. Los paises dinámicos del centro se benefician, con base en ello se llegó a la conclusión de que el intercambio comercial con los países industrializados perpetuaba las estructuras productivas de las economías periféricas, típicamente duales y heterogéneas. Para superar esta situación, se planteó que los países en vlas de desarrollo debían producir sus propias manufacturas. La ecuación básica de la CEPAL era la siguiente: "industrialización por sustitución de importaciones = desarrollo".

Despues de varias decadas de baberse puesto en marcha la estrategia sugerida por Prebish, la situación en los paises de América Latina no puede calalogarse como un rotundo éxito. Aunque no pueden negarse los logros que posibilito la industrialización, no logró cambiar la situación de subdesarrollo imperante. Siempre fue un grupo reducido el que salió favorecido y resultó una carga pesada para la mayoría de la población.

A la luz del presente (mediados de los noventa), al evaluar los resultados del desarrollismo, se pueden ver sus fallas que en resumidas cuentas son las siguientes:

- "La planificación secuencial de los procesos de industrialización nacionales estaba sesgada por el abanico de manufacturas que se habian importado tradicionalmente, es decir, por los patrones de consumo de minorías. 
- La priorización del establecimiento de industrias de bienes de consumo y el descuido de las industrias básicas y de bienes de capital, condujeron a aumentar la importación de bienes de capital y productos intermedios y primarios, lo cual impactó negativamente en las cuentas corrientes.

* Las industrias de bienes de consumo sustitutivos de importaciones enfrentaban una demanda interna limitada, lo que no les permitió lograr suficientes economías de escala; en consecuencia, producían a costos unitarios muy superiores a los niveles del mercado mundial, por lo que tenfan que ser protegidas contra la competencia externa mediante elevados aranceles y rígidos controles de cambio.

- La ausencia de competencia externa y las estructuras oligopolicas de los mercados permitlan la existencia de empresas demasiado pequeñas e improductivas que producian a costos excesivamente elevados y que, con el bajo uso de su capacidad instalada, descuidaban el avance tecnológico.

* La intervención directa e indirecta del Estado en el mercado provocó la dislocación de los precios relativos - en beneficio de la indusiria nacional y en perjuicio del sector agrario- que no reflejaba las relaciones de productividad y escasez intersectoriales" (Sangmeister, 1995).

En la década de los noventa, después de superar la crisis de la década perdjda y de dejar atrás la concepción desarrollista, en vista de su fracaso como motor de desarrollo, América Latina se encamina hacia una nueva concepción de desarrollo, en esta ocasión busca combinar una estrategia de modernización industrial productiva con apertura externa, en otras palabras, busca entrarle al concepto de 'ventajas competitivas dinámicas'. Para ello distingue entre la competitividad espúrea y efimera y la competitividad genuina o auténtica.

La nueva concepción representa un cambio importante al paradigma desarrollista, ya que éste indicaba que "para lograr el desarrollo primero habla que crecer internamente y después abrirse al mercado internacional"; en cambio, con el nuevo paradigma basado en la utilización de las NRT y de las ventajas competitivas dinámicas, la orientación cambia de sentido ya que ahora "para lograr el desarrollo primero hay que comenzar abriéndose al mercado intemacional"2.

En el sentido anterior, "las propuestas de apertura rápida y generalizada de la economía a la competencia externa y de sujeción de la actividad interna a los precios internacionales, ası como a la vigencia irrestricta de las señales de mercado, son el corolario de una concepción que considera rescatable sólo aquella parte de la industria capaz de resistir, a corto plazo, el impacto de la competencia internacional" (CEPAL, 1992).

Todo ello implica superar una serie de desaflos, ya que se trata de reencontrar el camino del desarrollo. Para ello es preciso: "fortalecer la democracia, ajustar 
las econom[as, estabilizarlas, incorporarlas a un cambio tecnológico mundial intensificado, modernizar los sectores públicos, elevar el ahorro, mejorar la distribución del ingreso, implantar patrones de ahorro más austeros de consumo, y hacer todo eso en el contexto de un desarrollo ambientalmente sustentable" (CEPAL, 1992).

El nuevo paradigma cepalino se basa en una integración selectiva en el mercado internacional, lo cual no debe ser entendido como un regreso al modelo exportador del tipo colonial, sino en el desarrollo y aseguramiento de una base selectiva de ventajas nacionales en la competencia de polos de desarrollo a nivel internacional, caracterizada por la capacidad de aprendizaje, la disposición innovadora y la diferenciación de productos, concentrándose en aquellas producciones que ofrezcan ventajas competitivas de cara al mercado internacional. Mediante una nueva política económica se pretende superar la mezcla, característica de América Latina en el pasado, de intervencionismo estatal con funcionamiento imperfecto del mercado, pues esta mezcla exigía demasiado del Estado, muy poco de la empresa privada y terminó por bloquear en lugar de promover el desarrollo. En consecuencia, el debate actual en América Latina debe aclarar y redefinir las relaciones entre el Estado y el sector privado.

La reorientación de la política económica implica: (a) mayor descentralización de la planificación económica; (b) prioridad del establecimiento del marco general del orden economico y de políticas de proceso ajustadas a reglas, en lugar de la intervención discrecional en los procesos dominantes en el pasado, y (c) polfticas tributarias, aduaneras y cambiarias neutrales ante los sectores. El objetivo de la privatización se encuentra estrechamente vinculado con el de disciplina fiscal, ya que existe gran cantidad de empresas públicas cuyo exceso de personal y pérdidas representaron, en el pasado, fuertes cargas presupuestarias adicionales. Además, el objetivo de privatización parte de la idea de que to importante no es el tamaño del sector público sino su eficiencia, y que el Estado deberfa dedicarse a las funciones que puede cumplir mejor que el sector privado" (Sangmeister, 1995).

En la concepción de la nueva política económica, la liberalización y desregulación de la economfa se entienden como herramientas para fomentar la competencia interna y, por ende, la eficiencia de la economia. También la idea de la integración regional y la estrecha cooperación económica adquieren un nuevo sentido en el marco de la reorientación conceptual de la polf́tica economica. No se pueden concebir a todos los intentos de integración, que en estos momentos han recobrado vitalidad, como intentos de procesos que van en contra del mercado mundial, sino como pasos intermedios en la vía de la integración en el mercado mundial. Ya se encuentra planteado que para el año 2005 deberá estar en funcionamiento la zona de libre comercio que abarque a todo el continente americano. 
Pero el aseguramiento de un relativo éxito en la implementación del nuevo paradigma tecnoeconómico en America Latina, implica que se opere una serie de transformaciones sociales, polf́ticas y económicas en otros ámbitos. Por ello, si los grupos económicos no abandonan por completo sus tradicionales conductas orientadas hacia la búsqueda de subsidios, y el Estado no hace uso decidido de su nueva función a fin de asumir su funciones plenamente y en forma autóno$\mathrm{ma}$, existe el peligro de que resulte un monstruo peor que el que se pretende superar. En consecuencia, se pueden identificar los siguientes factores de riesgo en las reformas de la política económica y de desarrollo en América Latina:

* "El cambio del paradigma económico no se estabilizará mientras no esté basado sobre un cambio de actitud de los actores en los niveles macro, mediano y micro; sin embargo, el retorno al pasado dorado del intervencionismo estatal, la industrialización por sustitución de importaciones y del populismo chocaría con los cambios macroeconómicos a nivel mundial que, en los últimos afios, han generado un pragmatismo neoliberal en América Latina.

* Lograr competitividad industrial y concentración como premisas de la integración selectiva en el mercado mundial, requiere niveles de capacidad de coordinación por parte del Estado y capacidad de autocontrol por parte del sector privado que aún no se han alcanzado en muchas economías de la región.

* La probabilidad de éxito de la integración selectiva en el mercado mundial no está determinada solamente de forma endógena por la disposición y capacidad de reforma de la política económica, sino también de forma exógena por la disposición de los países industrializados a eliminar su proteccionismo en los segmentos relevantes del mercado mundial.

- La desregulación del mercado laboral formal requiere que patronos y sindicatos, empresarios y trabajadores se traten como socios que negocian libremente las condiciones de empleo y trabajo en convenios globales.

- La liberalización radical e inmediata de las relaciones de intercambio puede provocar déficit sostenido en cuenta corriente, haciendo que América Latina dependa, una vez más, de la importación permamente de capital.

* En una estrategia de integración selectiva en el mercado mundial que apunta primordialmente a la exportación de materias primas y productos agrarios, manufacturas trabajo-intensivas y productos de mediana complejidad tecnológica, se debe tener en cuenta la competencia creciente en precios de otros países en vias de desarrollo que siguen estrategias similares.

- La especialización basada en recursos naturales bajo las condiciones imperantes en el mercado mundial puede provocar la explotación excesiva del medio ambiente; en consecuencia, reforzar el acceso privado no regulado a 
los recursos naturales con el fin de hacerlos valer en el mercado mundial podría tener consecuencias ecológicas catastróficas" (Sangmeister, 1995).

En todo lugar, la estrategia, aunque implica liberalización del mercado, requiere indispensablemente de nuevas formas efectivas de regulación estatal, es decir, de un nuevo tipo de Estado. En todo caso, debe limitar los costos sociales, polfícos y económicos de la transformación; las instancias estatales deben ampliar su autonomía y competencia para poder vigilar los mercados, fomentar la modernización tecnológica a través de políticas prácticas de educación e investigación, e imponer una polf́tica social compensatoria; debe incrementar la presión fiscal; debe tener claridad en el sentido de impulsar procesos democratizadores a todo nivel, darle un mayor nivel de participación a la sociedad civil, etc.

\section{Conclusión}

El futuro de América Latina no puede estar desligado de las repercusiones que le impone la NRT, ya que si transita en ella, su futuro dependerá de lo que las grandes empresas transnacionales decidan respecto a que es lo que la región debe producir para inserarse en las cadenas mundiales de produccion, es decir, decidirán cómo debe ser su inserción en el mercado mundial. Por otro lado, si decide no participar de lleno en el desarrollo de las fuerzas productivas que impone la NRT, su fuluro también dependerá de lo que las transnacionales produzcan y de cómo lo hagan, ya que las exportaciones de productos primarios que uadicionalmente le han garantizado un nicho en el mercado mundial, comenzarán a perder ventajas competitivas y se agravarán sus problemas de balanza de pagos.

La NRT, por lo tanto, es una Espada de Damocles que pende sobre los páses subdesarrollados en general, donde América Latina no es la excepción. Cualquier decisión que se tome al respecto implicará transformaciones y repercusiones de suma importancia, mismas que deben ser encaradas con objetividad y responsabilidad de parte de todas las sociedades; es una decisión que no puede quedar al arbitrio de unas pocas personas, sino que debe involucrar al grueso de la población. Por lo tanto, la decisión debe tomarse a traves de una politica de Estado y no de una simple polftica de Gobierno. Es una disyuntiva tan trascendental que no puede dejarse que la determinen únicamente los políticos, máxime si son politiqueros.

\section{Referencias bibliográficas}

Arbos, Xavier y Giner. Salvador. La gobemabilidad. Ciudadanía y democracia en la encrucijada mundial, Siglo XXI de España, 1993.

Bodemer, Klaus (compilador). Política tecnológica y modemización productiva, Venezuela: Editorial Nueva Sociedad, 1992.

Bonefeld, Werner y Holoway, John. "Posfordismo y forma social". En ¿Un nuevo Estado? Debate sobre la reesirucluración del Estado y el capital, en un libro compilado 
por ellos mismos. México: Editorial Cambio XXl, 1994.

CEPAL. Equidad y transformación productiva; un enfoque integrado, LC/G.1701 (SES.23/ 3), Chile, 1992.

(CIOSLORTT/CISLOIT). Crisis económica y revolución recnologica. Contiene los documentos de la conferencia Internacional sobre Crisis Económica y Revolución Tecnológica, celebrada en Rlo de Janeiro en noviembre de 1988 con los auspicios de los autores. Edición a cargo de ORT, 1989.

Godio, Julio. Sindicalismo iberoamericano: problemas, obsiaculos al cambio y búsqueda de nuevos rumbos, mimeografiado, sin fecha.

Herrera, Amilcar y otros. Las nuevas recnologías y el fururo de América Latina Riesgo y oportunidad, Mexico: Editorial de la Universidad de las Naciones Unidad y Siglo XXI, 1994.

Martinez, Eduardo. "Las interrelaciones entre la ciencia, la tecnologia y el desarrollo". En el libro compilado por el mismo Martínez Ciencia, recnología y desarrollo: interrelaciones teóricas y metodológicas, Caracas: Editorial Nueva Sociedad, Venezuela, 1995.

Mertens, Leonard. Crisis Económica y Revolución Tecnológica. Hacia nuevas estrategias de las organizaciones sindicales, Venezuela: Editorial Nueva Sociedad y ORIT, 1991.

OMINANI

Ovejero, Félix Lucas. Intereses de todos, acciones de cada uno. Crisis del socialismo. ecologia y emancipación, Madrid: Editorial Siglo XXI, España, 1989.

Reich, Robert. El trabajo de las naciones, Buenos Aires: Editorial Vergara, Argentina, 1993.

Sangmeister, Harmut. "El cambio de paradigmas: adios al desarrollismo y al cepalismo". Tomado del libro Cambio de paradigmas en América Latina: nuevos impulsos, nue. vos temores, Fundación Friedrich Ebert y Asociación Alemana de Investigación sobre América Latina, Venezuele: Editorial Nueva Sociedad, 1995.

Schuldt, Jürgen. "Revolución tecnológica, relaciones Norte-Sur y desarrollo". En el libro compilado por ALOP, Asociación Latinoamericana de Organizaciones de Promoción. América Latina: Opciones estratégicas de desarrollo, Venezuela: Editorial Nueva Sociedad, 1992.

Tangelson, Oscar. "Revolución teenológica y empleo: reflexiones para América Latina". En el libro compilado por Klaus Bodemer Polírica secnológica y modemización productiva, Caracas: Editorial Nueva Sociedad, Venezuela, 1992.

Thai-Hop. Pablo Nguyen. "La transformación tecnológica, gran desafio para los pobres", Mexico, revista Chris/us, No. 19, febrero, 1995.

Thurow, Lester. La guerra del siglo XXI. Head to head, Buenos Aires: Editorial Vergara, Argentina, 1992.

\section{Nolns}

I. Entre ellos: Leonard Mertens, Eduardo Martínez, Jürgen Schuldt, Robert Reich, Lester Thurow y CEPAL.

2. Dada, Héctor. Citado por José Franciseo Lazo en El Salvador. Papel de la Polfrica Gubernamental a través de las Finanzas Públicas: 1974. 1992. Tesis para obtener el grado de Doctorado en Ciencias Sociales de la Universidad Iberoamericana, México, 1995. 